\section{AS REPORTAGENS DAS MÍDIAS ESTRANGEIRAS SOBRE O BRASIL DOS MEGAEVENTOS ESPORTIVOS: SOFT POWER, PERIFERIA E DEPENDÊNCIA}

\author{
FOREIGN MEDIA REPORTS ABOUT BRAZIL'S MEGA SPORTING EVENTS: \\ SOFT POWER, PERIPHERY AND DEPENDENCE
}

LOS REPORTAJES DE LOS MEDIOS EXTRANJEROS SOBRE EL BRASIL DE LOS MEGAEVENTOS DEPORTIVOS: SOFT POWER, PERIFERIA Y DEPENDENCIA

\begin{abstract}
Palavras chave: Esportes.

Brasil.

Soft power.

Mídias sociais.

Sul Global.

Resumo: Neste artigo, a partir da análise de reportagens de nove jornais estrangeiros publicadas durante a Copa do Mundo e os Jogos Olímpicos realizados no Brasil, discutimos se a categoria soft power pode ser aplicada ao Brasil dos megaeventos esportivos. Consideramos que a categoria não pode ser aplicada em nações periféricas e deve ser repensada para países de economia dependente. Por isso, propomos de maneira embrionária uma redefinição da teoria de soft power. Neste contexto, surge a categoria "soft power heterodoxo". A partir de tal categoria, consideramos que os jornais analisados retrataram dois países em um mesmo território, um em 2014 e outro em 2016. Levantamos cinco hipóteses para compreender este fenômeno: organização, dimensão, características, logística, desinteresse. Ademais, este estudo evidencia que não há elementos que possam corroborar avanço no soft power do Brasil a partir das Copa do Mundo (2014) e dos Jogos Olímpicos (2016).
\end{abstract}

Keywords: Sports.

Brazil.

Soft power.

Social Media.

Global South.

Palabras clave: Deportes. Brasil.

Soft power

Medios de comunicación sociales.

Sur Global.
Abstract: In this article, based on the analysis of reports from nine foreign newspapers published during the World Cup and the Olympics held in Brazil, we discuss whether the category of Soft power can be applied to the Brazil of mega sporting events. We consider that it cannot be applied to peripheral nations and must be rethought for countries with dependent economies. Therefore, we propose an initial redefinition of the soft power theory. This context gives rise to 'heterodox soft power' category based on which we consider that the newspapers analysed portray two different countries in the same territory - one in 2014 and another one in 2016. We point out five hypotheses to understand this phenomenon: organization, size, characteristics, logistics, lack of interest. In addition, this study shows that there are no elements to corroborate advances in Brazilian soft power after the World Cup (2014) and the Olympics (2016).

Resumen: En este artículo, a partir del análisis de reportajes de nueve periódicos extranjeros publicados durante la Copa del Mundo y los Juegos Olímpicos realizados en Brasil, discutimos si la categoría soft powerpuede ser aplicada al Brasil de los megaeventos deportivos. Consideramos que la categoría no puede ser aplicada en naciones periféricas y debe ser repensada para países con economía dependiente. Por eso, proponemos de manera embrionaria una redefinición de la teoría de soft power. En este contexto, surge la categoría 'soft power heterodoxo'. A partir de esa categoría, consideramos que los periódicos analizados retrataron dos países en un mismo territorio, uno en 2014 y otro en 2016. Levantamos cinco hipótesis para comprender este fenómeno: organización, dimensión, características, logística, desinterés. Además, este estudio pone en evidencia que no hay elementos que puedan corroborar avance en el soft power de Brasil a partir de los megaeventos mencionados.
* Universidade de São Paulo (USP). São Paulo, SP, Brasil. E-mail: marcobettine@gmail.com; diegomonteirogutierrez@gmail.com

** Universidade Federal do Rio Grande (FURG). Rio Grande, RS, Brasil. E-mail: billygraeff@gmail.com

Recebido em: 30/04/2018 Aprovado em:14/11/2018

DOI https://doi.org/10.22456/1982-8918.82438 (c) (1) (8) Licence (c) (1) (8) Creative Commom 


\section{INTRODUÇÃO}

Neste artigo, buscamos discutir se a categoria soft power pode ser aplicada a nações periféricas como o Brasil. Para isso, analisamos as reportagens dos nove jornais internacionais mais acessados durante os Megaeventos Esportivos (ME) realizados no Brasil (BBC, CNN, New York Times, The Guardian, El País, El Mundo, Le Figaro, Le Monde, Daily Mail). Segundo a teoria de Nye (1990a), a mídia internacional teria papel importante para disseminar na sociedade global o conjunto de opiniões que podem definir a imagem de um país e, deste modo, interferir nas decisões da política internacional.

O conjunto das interpretações derivadas da compreensão crítica da bibliografia e a análise dos documentos a partir destas interpretações nos levou a evidenciar, a partir do referencial proposto, que a categoria soft power, da forma utilizada por Nye (1990a, 1990b, 2004, 2009, 2018), não pode ser aplicada a países periféricos. Por este motivo, propomos de maneira embrionária e provocativa, que merece a análise crítica dos pesquisadores preocupados com temas como a dependência da América Latina, uma redefinição da teoria de soft power.

A partir desta redefinição propomos o conceito "soft power heterodoxo", chegamos a quatro subáreas de análise que permitiram as formulações constantes deste trabalho: (a) Soft power no contexto do mundo globalizado; (b) Utilização dos ME pelas nações periféricas para incrementar seu soft power, (c) Mídia Internacional como fator de impacto na avaliação do Brasil no exterior e possível influência no seu soft power, (d) Aplicação da teoria do soft power a nações periféricas como o Brasil.

\section{SOFT POWER NA POLÍTICA INTERNACIONAL}

Nos estudos tradicionais sobre o soft power, a nação é a protagonista das relações internacionais, agindo de forma coesa e racional (CAMPBELL; O'HANLON, 2006; COOPER, 2004).

Nye (1990a, 1990b) irá entender o poder como algo fluido, neste sentido os elementos intangíveis ganham força na construção de seu conceito de soft power (HUANG, DING, 2006, p.33). Segundo os autores tradicionais, a teoria de Nye se mostra uma boa ferramenta para a análise do novo cenário internacional com o crescimento dos BRICS (Brasil, Rússia, Índia, China e África do Sul) (HOLSTI, 1985). Neste alinhamento político, o conceito de fluidez legitima o soft power, pois considera a coerção militar e econômica menos efetiva na busca por prestígio e influência internacionais, permitindo que as nações busquem seus objetivos por outros caminhos e possam ascender dentro da ordem estabelecida sem necessariamente destruir suas instituições e acordos (LAFER, 1982; NYE, 2004). Ainda segundo estes estudos, os ME são uma vitrine para o desenvolvimento do soft power, pois através dos eventos um país-sede poderá divulgar sua imagem para o mundo e, através dos valores universais dos jogos, atingir uma audiência midiática global (GRIX, LEE, 2013; GRIX et al., 2015).

Nye divide as fontes de soft power em três categorias principais: cultura, valores políticos e política internacional (NYE, 2008). Os ME apresentam uma grande oportunidade para estar nos holofotes da política internacional nesses três aspectos. A cultura é divulgada pelo evento com um todo, com um grande número de turistas passeando pelo país e tendo contatos com suas mais diferentes manifestações. Os eventos de abertura e encerramento 
constituem o ápice, com apresentações cada vez mais apoteóticas que têm como objetivo exibir os feitos e as qualidades da nação. Os valores políticos são divulgados na organização da competição e no funcionamento das instituições.

Em nosso posicionamento, afirmar que o ME é uma das formas de alavancar o soft power do país-sede deve ser considerado no mínimo delicado, visto que, pela sua importância cada vez maior, sediá-los envolve mudanças nos mais diversos aspectos do país, desde mobilidade urbana e habitação, até políticos e jurídicos (HORNE, 2017; HORNE; MANZENREITER, 2006; MÜLLER, 2015; PREUSS, 2007). $O$ gasto de bilhões de dólares, o suposto lucro e uma audiência massiva não representam, por si só, o sucesso do evento, podendo resultar em enormes fracassos, como análises feitas em Sochi, África do Sul e China (AHLERT, 2007; CORNELISSEN, 2010; 2011; PREUSS, 2007; ALMEIDA; GRAEFF, 2016; ZIAKAS, 2015). A análise heterodoxa que proporemos neste estudo partiu das contradições que identificamos entre a relação causal dos ME e o uso do conceito soft power. Apresentaremos três estudos que nos auxiliaram a pensar tal análise. O primeiro é de autoria de Manzenreiter (2010), 0 segundo de Preuss e Christian (2011). Ambos apontaram, a partir de dados globais, o fraco impacto da transformação da percepção das pessoas do Ocidente sobre a sociedade chinesa, afirmando que não ocorreu o incremento do soft power da China a partir Jogos Olímpicos (JO) de Pequim 2008. O terceiro, de Brannagan e Giullianotti (2014), afirma que o Qatar, ao buscar utilizar a Copa do Mundo (CM) de 2022 para se firmar como nação amiga do Ocidente, está, pelo contrário, perdendo soft power pelos problemas que estão ocorrendo durante as obras.

A partir deste cenário estabelecemos duas hipóteses: a primeira, alinhada à tradição de Nye, diria que o soft power poderia ser aumentado ou reduzido a depender da performance da nação. A segunda, não alinhada à tradição de Nye, diria que a teoria tradicional não contempla nações periféricas e que Nye e seus colaboradores a construíram a partir da visão do Pentágono, o cérebro militar dos Estados Unidos da América (NYE, 2009), e, portanto, uma outra análise sobre soft power se faz necessária.

Assim, interpretamos o soft power a partir de uma literatura crítica da Sociologia, da globalização e da periferia (BRANNAGAN; ROOKWOOD, 2016; GRIX et al., 2016; GRIX; LEE, 2013; MBEMBE, 2001; MIGNOLO, 2007). Para termos base empírica para desconstruir o conceito de soft power, analisamos as reportagens de nove jornais de diferentes línguas (inglesa, francesa e espanhola), os mais acessados da internet no período do evento'.

Ao todo, foram utilizadas 480 reportagens sobre a CM e 242 reportagens sobre os JO. Os artigos de jornais escolhidos discutiam questões sociais, políticas e econômicas do Brasil durante os ME. Buscou-se, com isso, entender que tipo de imagem a imprensa estrangeira iria apresentar sobre o Brasil e quais seriam os eventuais impactos que eventos desta magnitude trariam para a imagem do país no exterior.

Ao ler e categorizar as reportagens, percebemos que a mídia apresentou ao mundo dois Brasis, um na CM e outro nos JO. Em dois anos, as representações exibidas mudaram radicalmente. Como então construir uma categoria tão fluida como soft power, que se molda de acordo com os interesses editoriais dos jornais? Na nossa opinião é preciso construir

\footnotetext{
1 A escolha destes jornais foi feita pelo site Alexa, empresa responsável por medir o tráfego na internet, que produz o ranking dos quinhentos

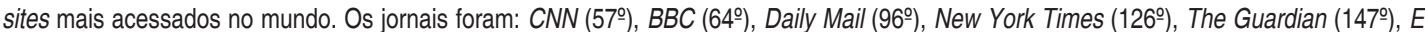

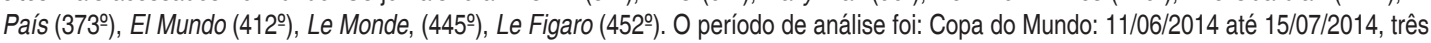
dias antes de iniciar a Copa do Mundo de 2014 até três dias depois de terminada e, Jogos Olímpicos: 04/08/2016 até 22/08/2016, três dias antes de iniciar os Jogos até três dias depois de terminado.
} 
uma categoria de análise, como a aqui proposta, que tenha um posicionamento crítico frente à vinculação das notícias pelas mídias e que "[...] entenda 0 jornal como representante de interesses políticos e econômicos"2 (MUNDIM, 2018, p.9).

Por este motivo, propomos reconstruir a categoria a partir do olhar de uma nação periférica, demonstrando que as análises feitas por Nye são parte do processo de afirmação do poder e que não podem ser utilizadas para analisar países que não detêm o poder econômico e militar para impor as suas agendas, por exemplo, aos meios de comunicação de massa internacionais. Portanto, para fins deste trabalho, e nos limites desta pequena análise, o "soft powerheterodoxo" é uma categoria de poder nas relações internacionais, particularmente poder burocrático no sentido weberiano do termo, aplicado à política entre países desenvolvida por Hans Morgenthau (2003), definindo poder como luta entre forças que não são necessariamente antagônicas, já que querer o poder é ter e se manter no poder, independente de ideologia; avançamos os estudos de Morgenthau para ampliar a ideia do poder como fim em si.

Para Morgenthau, a nação se utiliza de elementos de cooptação cultural e social para impor sua força no jogo político internacional. "A política é a manifestação de uma luta pelo poder, e é justificada em termos éticos, legais ou biológicos" (MORGENTHAU, 2003, p.173). Acrescentaríamos a essa definição aspectos sociais e culturais. Neste sentido, teria mais "soft power heterodoxo" aquela nação que consegue fazer prevalecer sua cultura às demais nações. Como a nação dominante está no coração e nas mentes das nações dominadas, ela poderia exercer seu poder por meio dos princípios do soft power tradicional. Em último caso, o soft power só poderá ser utilizado se houve em sua base primeira violência, imposição e força, de uma nação dominante sobre a dominada. Seria a neocolonização da própria cultura em uma sociedade globalizada (MBEMBE, 2001; MIGNOLO, 2007).

Portanto, a categoria soft power aqui desenvolvida é heterodoxa, vista pelo olhar do colonizado, dominado, distante da escola neorrealista das relações internacionais, onde o soft power seria limpo e o hard power sujo. Exemplo disto é a experiência de um país periférico querer ser sede de uma CM ou dos JO, o que demonstra este exercício de poder controlado, alinhamento e dependência.

\section{BRASIL E OS MEGAEVENTOS ESPORTIVOS}

Um grande desejo do Brasil, ou pelo menos de parte do país, sobretudo daqueles envolvidos em processos decisórios na esfera macro, foi realizado. O país sediou os primeiros JO da América do Sul, e em dois anos tivemos nas terras tupiniquins dois dos maiores eventos mundiais, em 2014 a CM e em 2016 os JO (AQUINO, 2009).

A CM de 2014 inicia, sob a ótica dos jornais analisados, com uma grande dúvida, principalmente devido aos protestos (jornadas de junho) na Copa das Confederações em $2013^{3}$.

2 Partimos de algumas premissas para afirmar que os jornais representam interesses políticos e econômicos. Nos estudos de Mundin sobre "O viés da cobertura política da imprensa nas eleições presidenciais brasileiras de 2002, 2006 e 2010" o pesquisador nos possibilitou compreender o viés da cobertura midiática, e este viés midiático é resultado da "falta de equilíbrio" que ocorre quando um lado da história recebe mais atenção do que outro; ou ocorre um tratamento diferenciado de um acontecimento, partido ou lado da questão durante um longo período de tempo; ou o jornal é seletivo. Temos que pensar que a grande imprensa atual está estruturada de forma empresarial num mercado de informação bastante competitivo e sua fonte de financiamento depende basicamente da circulação e dos anunciantes.

3 Avritzer (2016), Bastos, (2017), Dantas, (2016) e Szwako (2016), discutindo os impasses da democracia no Brasil, nos mostram uma leitura bem consistente dos protestos de 2013 ao golpe de 2016 - nós estendemos a leitura proposta para o processo eleitoral de 2018 . Discutem os autores, em cada um dos seus artigos, que a mobilização verde-amarela que ganhou as ruas nos meses de março, abril e agosto de 2015 soube se apropriar de um dos principais legados de 2013: a rua como palco legítimo dos protestos. Aos gritos de "Fora Dilma" e "Fora PT", uma massa de entusiasta fascista foi alimentada por movimentos de direita que, como se sabe hoje, foram e são ligados a partidos golpistas e a grupos ultraconservadores, utilizando o denuncismo seletivo de uma corrupção sistêmica do Estado como ideia-força para articular grande 
Houve ampla discussão sobre o momento político brasileiro (eleição presidencial) e pôs-se em dúvida inclusive a centralidade do futebol na vida do brasileiro. Foi neste cenário de incertezas que a mídia buscou trilhar sua linha editorial nos primeiros dias da CM. $O$ interessante foi notar que enquanto a CM transcorria sem incidentes, isto é, os protestos estavam devidamente controlados (reprimidos), os ingressos, mesmo dos jogos secundários, estavam esgotados, e os espectadores davam mostras de felicidade incomensurável, houve uma mudança na linha editorial de quase todos os veículos analisados. Como exemplo El Mundo no artigo "El fútbol y Brasil" (MAYOR, 2014).

A BBC, em 16 de junho, dois dias depois de começada a Copa, faz o seguinte comentário: "Então, todos nós [imprensa] que passamos o ano passado informando sobre o caos, atrasos e manifestações, estávamos errados? O Brasil provou aos duvidosos e críticos que este país está pronto para hospedar um evento dessa magnitude" (DAVIES, 2014).

O New York Times aponta que as desgraças dão lugar a pequenos problemas:

Os estádios não estariam prontos a tempo. Violentos protestos de rua ameaçariam os fãs e os políticos. As greves nos aeroportos e no metrô atrapalhariam dezenas de milhares de visitantes. Estas, e outras previsões que lembravam o dia do juízo final, eram preocupações perpétuas nos dias que antecederam a Copa do Mundo no Brasil. Mas depois de quase uma semana de jogos, a situação no maior país da América do Sul não é sombria. Para os adeptos que gostam de locais atraentes, resultados surpreendentes e futebol elegante, este torneio, até agora, foi um sucesso incrível. Os jogos são apaixonantes e o drama foi perfeito para televisão (BORDER, 2014) (tn).

No dia 21 o El País afirma que as críticas à organização do evento não eram para tanto:

[...] em geral, o campeonato se desenvolve pontualmente, de uma maneira brilhante, as ruas estão repletas de fãs felizes envolvidos em uma atmosfera cada vez mais festiva. E é por isso que a certeza está sempre mais firmemente enraizada, mesmo para os brasileiros desconfiados, que não era para tanto (BARCA, 2014) (tn).

O Le Monde afirmará que a improvisação brasileira superou as inquietações:

Nos estádios todas as preocupações parecem ter desaparecido nos primeiros acordes da cerimônia de abertura. Depois de um pouco mais de uma semana de competição, parece que o desastre anunciado não ocorreu. Claro, falta aqui ou lá o último acabamento, a última camada de tinta. Mas um sorriso faz você esquecer um azulejo que está faltando, um 'bem-vindo' compensa um flanco de soquete ou uma rede telefônica com defeito. Um polegar para cima, signo que significa que está tudo bem, adeus e tudo está ok, serve como esperança para comunicar seu bom humor (HERNANDEZ; HOPQUIN; BOURCIER, 2014).

A CNN buscou fazer um panorama geral da $\mathrm{CM}$ por meio entrevistas com estadunidenses que vieram ao Brasil - que elogiaram a hospitalidade e a beleza do país -, terminando com uma entrevista com a então presidente Dilma Roussef sobre a CM e as perspectivas para 2016, na qual Roussef afirmou que "fizemos a melhor Copa de todos os tempos e faremos a melhor Olímpiada" (DARLINGTON, 2016).

O Daily Mail fez um balanço mais geral, afirmando que a Copa foi um sucesso, com o cuidado de apontar que é a Copa das elites, e compara as críticas que o Brasil teve às que ocorreram na África do Sul: 
Como modelo de igualdade social, então, esta Copa do Mundo alcançou pouco. Como um evento esportivo, no entanto, passou seu teste confortavelmente e graças à beleza do futebol - espetacularmente. Isto, lembre-se, deveria ser a Copa do Mundo que não funcionaria. Era para ser o torneio onde os estádios não estavam preparados, onde não teria infraestrutura e onde os fãs de futebol visitantes perderiam suas carteiras e telefones celulares.

Eles disseram tudo isso antes da África do Sul, é claro, e, assim como não aconteceu, não aconteceu aqui (LADYMAN, 2014) (tn).

O The Guardian fez uma abordagem destacando uma reportagem feita pelo jornal no auge dos protestos de 2013 (Copa das Confederações) mostrando que as previsões catastróficas não ocorreram:

A situação política é complexa. A presidente Dilma Rousseff foi xingada e submetida a cânticos obscenos durante a partida de abertura, mas isso foi tanto devido a uma multidão de São Paulo, que não apoia suas políticas socialistas. Enquanto isso, sindicatos e grupos de esquerda usaram a Copa do Mundo como plataforma. As coisas podem mudar se o Brasil sair [da Copa], mas, por enquanto, os protestos em São Paulo, Porto Alegre e outros lugares permaneceram pequenos e o humor é em grande parte comemorativo.

Para além dos torcedores, as tensões no país permanecem, mas Ito [cartunista do jornal] novamente captou o humor com seu último trabalho: uma família, incluindo um manifestante com uma bandeira 'fuck Fifa', lotando a sala de televisão assistindo a Seleção (GIBSON, 2014).

Juntamente com o The Guardian, que traz 0 aspecto da alienação do brasileiro na Copa, o El Mundo fez duras críticas à parte endógena da organização, como a corrupção, as dívidas e os objetivos enquanto país:

[...] o Brasil tem vivido uma ilusão: o futebol escondeu a realidade do país por alguns dias. 0 ex-presidente Lula da Silva, que promoveu a Copa do Mundo e os próximos Jogos do Rio, aproveitou a situação internacional para vender 0 milagre do Brasil: a maior economia emergente das Américas. Mas ele abusou das medidas populistas e do recurso à dívida, o que gerou burocracia e corrupção. Sua discípula Rousseff nunca considerou corrigir a situação. A pobreza e a desigualdade continuam a ser a grande questão não resolvida do Brasil. Apesar da Copa do Mundo (EDITORIALES, 2014).

Diferentemente da mudança da linha editorial de todos os jornais analisados, sobre a questão do sucesso do evento e a capacidade organizacional do Brasil para sediar a CM (mesmo com a queda da ponte em Belo Horizonte, invasão de campo em Recife e alagamentos em Cuiabá, Recife, Porto Alegre e Natal), nos JO só existiram críticas. A grande preocupação do COI eram duas: (a) a infraestrutura mínima para o evento estaria pronta (estádio, vila olímpica, Baía de Guanabara, etc.)? e (b) o processo de impedimento que culminou no Golpe Parlamentar de 2016 (JINKINGS, DORIA, CLETO, 2016; SOUZA, 2016) e seus protestos (contra e a favor) inviabilizariam os jogos?

Os jogos ocorreram, mas faltaram adjetivos para os jornais destacarem os problemas do Rio 2016. Manifestações políticas, estádios vazios, acidentes no entorno dos estádios, protestos nas ruas, violência urbana, falta de infraestrutura básica para os atletas, problemas básicos como o tratamento da água da piscina no complexo olímpico, erro na drenagem na pista de atletismo, são quase 150 reportagens de crítica à infraestrutura dos JO. Analisaremos algumas reportagens que tratam dos problemas mais citados durante o evento, e poderemos compreender claramente a mudança do humor dos jornais passados dois anos da CM. 
A festa de abertura não foi suficiente para apaziguar as críticas, discutiu-se: (a) para quem era a abertura?, (b) como um país extremamente desigual fala de igualdade de direitos?, (c) como um país que tem níveis alarmantes de violência sexual, feminicídio, ataque a homossexuais vai discursar sobre o respeito à diversidade?, (d) como um país que está destruindo a floresta amazônica vai discutir mudanças climáticas?

'Estamos perto em distância, mas longe': os moradores de favelas do Rio são obrigados a assistir à cerimônia de abertura brilhante nos telhados de suas casas degradadas. Em Mangueira, uma favela no leste do Rio, atordoada pela violência das gangues e a pobreza, os moradores olharam para a arena a partir de telhados, separados do espetáculo por uma estrada e trilhos de trem (TINGLE, 2016) (tn).

Este é o país nos ensinando as mudanças climáticas? O Brasil tenta ensinar o mundo uma lição, apesar da água horrivelmente poluída e do desmatamento da Amazônia. As Olimpíadas do Rio começaram com uma atmosfera de festa na sexta-feira, mas [a abertura] foi apontada como hipócrita. (PLEASANCE, 2016).

A Maranhão [Joana Maranhão, nadadora brasileira] é um alvo particular [em jornais e redes sociais brasileiras] de conservadores de direita porque expressou apoio para a presidente do Partido dos Trabalhadores suspensa, Dilma Rousseff, e criticou dois dos mais importantes deputados da direita: Jair Bolsonaro (que provocou Dilma por sua tortura durante a ditadura) e Marco Feliciano (quem foi acusado na semana passada de abuso sexual). (WATTS, 2016a) (tn).

Até agora [14 dias de evento], cinco pessoas foram mortas, várias feridas e milhares de pessoas impedidas de trabalhar, estudar, porque estão assustadas, aterrorizadas e suas casas estão sendo invadidas... 0 nome disso é o genocídio, 0 extermínio e 0 abate. [...] Outra residente da Maré disse que havia problemas semelhantes em outras favelas, mesmo aquelas que deveriam ter sido 'pacificados' pelas unidades policiais. 'O legado que temos de megaeventos na Maré é sangue no chão, disse ela. 'Estes jogos não incluem favelas, comunidades periféricas e os pobres. Só devemos trabalhar, servir, não se divertir'. [...] Bem antes dos Jogos, as organizações de direitos humanos advertiram sobre os perigos potenciais. Amnesty disse que a polícia do Rio matou mais de 2.500 pessoas desde que os Jogos foram premiados em 2009, incluindo mais de 100 neste ano, a maioria dos quais eram jovens negros. Disse que as medidas de repressão tendem a aumentar durante megaeventos (WATTS; DOUGLAS, 2016) (tn).

Para termos uma ideia da dimensão destas discussões, se contarmos em números de reportagens o tema desigualdade e violência policial na imprensa analisada foram os seguintes: Daily Mail 26; The Guardian 13; NYT 19; BBC 5; CNN 8; Le Figaro 6; Le Monde 12; El Mundo 10; El Pais 2.

Pensando a partir da categoria "soft power heterodoxo", as instituições brasileiras não parecem se adequar à lógica da ideia subjacente ao termo soft (brando), pois houve um esforço do Estado para a pacificação das favelas via guerra civil velada. Pensando na política doméstica, parece não haver dúvida de que o esforço do Estado do Rio de Janeiro para "pacificar" as favelas, principalmente após 2009 (data da escolha da sede dos jogos), teve efeitos devastadores para a vida dos moradores, mostrando que há uma lei própria nestes territórios e que o poder público entra pela violência, e não pelo saneamento básico, unidades básicas de saúde, escolas.

O jornal EI Mundo, com uma ironia típica, faz uma severa crítica à ideia de diversidade no Brasil, com a manchete "Família tradicional brasileira", o jornal discute como não há espaço 
para outras formas de família que não o modelo "papai-mamãe e filhos felizes", contrapondo a diversidade da cerimônia de abertura:

É curioso ver tantas pessoas - geralmente pessoas brancas de classe média ou fervorosos evangélicos - defendendo esse estilo de vida e até mesmo chamando-a de 'família tradicional brasileira' em um país onde é mais difícil encontrar um homem casado apenas uma vez que um esquiador em Salvador, Bahia. Separação e infidelidade parecem pecados mais perdoáveis no Brasil (ARANDA, 2016) (tn).

O que de fato ocorreu? O encanto ao Brasil terminou em dois anos, ou temos outros indicadores que podem sugerir que não somente existiu de fato um problema organizacional, mas, também, uma conjuntura específica que pode auxiliar a entender essa mudança dos jornais abordarem os eventos no Brasil.

Vamos apontar algumas hipóteses: (1) Organização: a CM estava melhor organizada e o Brasil ainda respirava uma aura de instituições que funcionavam. Ao contrário, durante os $\mathrm{JO}$, o evento estava mais desorganizado e o Brasil apresentava sinais de quebra institucional com a destituição de uma presidente eleita (JINKINGS, DORIA, CLETO, 2016; SOUZA, 2016). (2) Dimensão: na CM os jornalistas viajavam por grande parte do Brasil e em cada local eram publicados cadernos sobre onde a sua seleção nacional iria jogar, falando da cultura local, da recepção, das belezas naturais, portanto, havia uma potencial agenda positiva, já que os locais onde se realizaram a Copa são locais extremamente encantadores; já nos JO, todos os jornais e correspondentes ficavam em um mesmo local, convivendo durante cerca de um mês com as mazelas da população, e onde a divisão e a desigualdade sociais são muito evidentes.

(3) Características: assim que a seleção nacional, na CM, era eliminada e voltava para casa, o jornal automaticamente utilizava correspondentes de outras agências para comentar sobre a $\mathrm{CM}$, diferentemente deste cenário, nos $\mathrm{JO}$, os correspondentes ficaram até o último dia do evento. (4) Logística: para as mídias a CM é um evento muito mais caro em termos de logística e recursos humanos, e a maior parte dos jornais optou por ter duas equipes de jornalismo, uma que cobria a sua seleção e outra que cobria o evento de modo generalista, muitas vezes usando (comprando) notícias locais para ampliar as suas publicações, os $\mathrm{JO}$ em termos de gastos e logística para as mídias é menor, podendo os correspondentes se ater mais a questões alheias ao evento, como a fome, distribuição de renda, Golpe Parlamentar, protestos, problemas estruturais, pois havia uma convivência próxima entre o evento e os jornalistas e os jornalistas entre si. (5) Desinteresse: pensar que o namoro das grandes potências com o Brasil terminou e as grandes corporações perderam o interesse no Brasil, portanto, as mídias acompanharam estes humores, não havia uma pressão para que o evento parecesse que estava ótimo e que não havia problemas, como foi na CM.

Acontecimentos como 0 ataque a um ônibus oficial de jornalistas estrangeiros na primeira semana do evento foram marcantes em tal trajetória também. BBC (WORLD LATIN AMERICA, 2016): "Houve um barulho estaladiço, quando o ônibus foi atingido. Havia buracos perfurados no vidro quando aconteceu" (tn). CNN (ROBERTS, 2016): "Um ônibus do Rio 2016 transportando jornalistas foi atingido por um objeto que quebrou as janelas na noite de terçafeira, deixando duas pessoas feridas" (tn). El País (AMENA, 2016): "Atacado no Rio um ônibus oficial que transporta os repórteres" (tn). Le Figaro (THAYALAN, 2016): "Na terça-feira, um ônibus transportando jornalistas foi atacado" (tn). Não há espaço nem interesse de trazer todos os jornais, utilizamos apenas um de cada país para reforçar que as notícias nos Jogos se 
reproduzem nos jornais analisados, enquanto há uma maior pulverização de temáticas na CM, o que reforçaria as hipóteses discutida acima.

Sobre a organização dos eventos podemos considerar que ambos tiveram problemas graves, mas, ao nosso ver, o que a mídia internacional retratou é que a CM foi um sucesso e os JO um desastre.

A notícia mais reproduzida pelos meios de comunicação analisados sobre os $\mathrm{JO}$, na questão de infraestrutura, foi a piscina verde do parque olímpico Maria Lenk, mas podemos apresentar cada uma das notícias referentes ao Rio de maneira bem rápida, Le Figaro: "Plongeon olympique: Le mystère de l'eau devenue verte"; El Mundo: "El 'Call of Duty' carioca". Le Monde: "JO de Rio : la chute d'une caméra officielle fait sept blessés dans le parc Olympique". CNN: "Rio athletes deal with water full of sewage and trash". BBC: "Rio Olympics Marred By Pollution". NYT: "Rio Olympics: Stray Bullet Flies Into Equestrian Media Center". The Guardian: "Empty seats all around Rio 2016 Olympic Stadium as athletics begin". Daily Mail: "Olympic tourists caught up in gun battle between criminals and police in shopping mall". El Pais: "Objetos flotadores no identificados". O Le fígaro fala da piscina verde; o El Mundo da violência urbana no Rio; o Le Monde da queda da câmera no parque olímpico; a CNN fala da poluição da Baía de Guanabara, a BBC da poluição no Rio de Janeiro; o NYT da bala que atingiu o centro equestre; The Guardian dos assentos vazios na maior parte das competições; Daily Mail da guerra entre a polícia e os traficantes em locais turísticos; El País fala de objetos que atrapalhariam os velejadores. Fatos que corroboram as hipóteses apresentadas.

As notícias sobre a CM, como apontado anteriormente, tiveram uma virada e os veículos começaram a abordar diferentes perspectivas sobre o Brasil, o futebol e o evento. O Daily Mail entrevista uma série de pessoas em São Paulo perguntando como elas se prepararam para a CM, no artigo "As vidas coloridas dentro do Brasil louco pelo futebol. Um olhar sobre a vida cotidiana do povo de São Paulo" (TRAVELMAIL REPORTER, 2014) (tn). Outro artigo que aborda a questão da infraestrutura, os hotéis caros, apresenta uma alternativa: "Os residentes da favela fazem a Copa do Mundo trabalhar para eles com estadias domiciliares para os fãs. Alguns torcedores estão evitando os hotéis caros do Brasil e dizem que se sentem mais seguros na favela do que na praia de Copacabana" (FREEMAN, 2016) (tn). "A paixão do Brasil pelo futebol ainda é evidente. Os brasileiros compraram a maioria dos 2,5 milhões de ingressos apesar dos altos preços. Alguns protestos locais provavelmente acontecerão, mas não na escala do ano passado" (PEREIRA, 2014) (tn).

Nos JO o mesmo Rio de Janeiro é retratado de outra forma: "A falta de saneamento básico nesta cidade de 12 milhões de pessoas é principalmente devido à infraestrutura ruim e ao planejamento urbano caótico décadas atrás" (ASSOCIATED PRESS, 2016) (tn).

A polícia militar e civil do Rio de Janeiro realmente é a mais violenta do mundo? Essa é a conclusão de estudos separados divulgados pela Anistia Internacional e pela Human Rights Watch no início deste ano. Eles acusam as forças policiais do Rio de Janeiro de torturar rotineiramente e matar cidadãos - especialmente jovens negros - durante a prisão. Eles também dizem que o problema está ficando muito pior à medida que as Olimpíadas se aproximam (MUGGAH, 2016) (tn).

O único soft power que o Brasil poderia promover seria o das nações dominantes. Mas o Brasil não é uma força dominante no cenário internacional. Assim, ao sediar os jogos, o Brasil reforça o poder daqueles que possuem uma cultura imperialista desenvolvida e que podem se beneficiar das formas complexas de se decidir sobre os destinos das periferias. 
Nas páginas dos jornais, o elemento desigualdade é tratado constantemente com auras de se conhecer o desconhecido, ou colocar com clareza como o Brasil é periférico, ou lançar um olhar ocidental civilizador de que estamos sujeitos a todos os tipos de intempéries.

\section{CONSIDERAÇÕES}

O artigo buscou problematizar o conceito de soft powercomo forma de poder mobilizado e exercido nas relações internacionais pelas nações desenvolvidas no contexto de realização de megaeventos esportivos no Brasil. Aplicando a teoria de periferia e dependência discutimos a forma de exercício de poder da grande imprensa internacional durante a realização da Copa do Mundo 2014 e dos Jogos Olímpicos 2016.

O trabalho teve como escopo discutir se a categoria soft power pode ser aplicada a nações periféricas como a brasileira. Para isso, utilizamos o referencial teórico em diálogo com dados extraídos de nove jornais de relevância e de influência da mídia internacional. Consideramos que é necessária uma redefinição do conceito soft power, propomos a ideia de um "soft power heterodoxo" para quando se tratar de países periféricos. Conforme apontado, amparamos nossa análise em cinco hipóteses, identificou-se um olhar de dominador sobre o dominado na cobertura da mídia internacional com relação ao Brasil dos megaeventos esportivos.

Buscamos analisar e compreender as reportagens de mídias internacionais publicadas durante a $\mathrm{CM}$ e os $\mathrm{JO}$ que versavam sobre aspectos políticos, sociais e econômicos da sociedade brasileira, a partir da categoria desenvolvida aqui, denominada soft power heterodoxo.

Construímos esta categoria a partir da análise de poder burocrático weberiano, aplicado à teoria de poder nas relações internacionais por Morgenthau, e aprofundamos a ideia de busca de poder pelo poder. Deste modo, o "power" em soft power foi explicado. Por sua vez, o termo "soff' de Nye ancora-se em valores culturais. Dialogamos com Mbembe e Mignolo para questionar "os valores culturais" entendidos por nós como sendo imperialismo, dominação, dependência e cooptação pelo "power" definido anteriormente. Violência mais imposição cultural é igual a soft power. Assim, afirmamos a impossibilidade do uso do conceito soft power em sua forma tradicional para se analisar a evolução da participação de nações em desenvolvimento no cenário internacional.

Ademais, as reportagens analisadas retrataram dois países em um mesmo território, um em 2014 e outro em 2016, construindo uma imagem manipulada do país no contexto internacional. Levantamos cinco hipóteses para compreender tal manipulação: organização, dimensão, características, logística, desinteresse. A partir de tais hipóteses foi possível entender que a imagem do Brasil pôde ser manipulada de inúmeras maneiras ${ }^{4}$. 


\section{REFERÊNCIAS}

AHLERT, Gerd. Assessing the Impact of the FIFA World Cup Germany 2006TM: Some Methodological and Empirical Reflections. GSW discussion papers, 2007/2. Disponível em: $<$ https://www.econstor.eu/bitstream/10419/94418/1/gws-paper07-2.pdf>. Acesso em: 18 dez. 2018.

ALMEIDA, Bárbara Schausteck de; GRAEFF, Billy. Displacement and Gentrification in the "City of Exception": Rio de Janeiro Towards the 2016 Olympic Games. Bulletin Journal of Sport Science and Physical Education, v. 70, p. 54-61, 2016.

AMENA, Aldo. Atacado en Río un autobús oficial que traslada a los periodistas. El País, Madri, Juegos Olímpicos, 10 agosto 2016. Disponível em: <https://elpais.com/elpais/2016/08/10/ videos/1470836498_497153.html>. Acesso em: 05 jan. 2019.

AQUINO, Yara. Lula: Olimpíadas serão oportunidade única para o Brasil. Rede Brasil Atual, 2009. Disponível em: <https://www.redebrasilatual.com.br/esportes/jogos-olimpicos/lula-olimpiadasserao-oportunidade-unica-para-o-brasil>. Acesso em: 17 dez. 2018.

ARANDA, Germán. Familia tradicional brasileña. El Mundo, Madri, 18 agosto 2016. Disponível em: <https://www.elmundo.es/deportes/2016/08/18/57b4e86e46163fcd778b4588.html>. Acesso em: 5 jan. 2019.

ASSOCIATED PRESS. At a school in Rio's slums, kids surf in toxic waters. Daily Mail, Londres, 14 agosto 2016. Disponível em: <https://www. dailymail.co.uk/wires/ap/article-3740225/At-schoolRios-slums-kids-surf-toxic-waters.html>. Acesso em: 5 jan. 2019.

AVRITZER, Leonardo. Impasses da democracia no Brasil. Rio de Janeiro: Civilização Brasileira, 2016.

BARCA, Antonio Jiménez. No era para tanto. El País, Madri, Mundial 2014, 21 junho 2014. Disponível em: <https://elpais.com/deportes/2014/06/21/mundial futbol/1403367068 619144.html>. Acesso em: 05 jan. 2019.

BASTOS, Pedro Paulo Zahluth. Ascensão e crise do governo Dilma Rousseff e o golpe de 2016: poder estrutural, contradição e ideologia. Revista de Economia Contemporânea, v.21, n.2, p. 1-63, 2017.

BORDER, Sam. At the World Cup, Doomsday Predictions Give Way to Smaller Hiccups in Brazil. New York Times, New York, 17 Junho 2014. Disponível em: <https://www.nytimes. com/2014/06/18/sports/worldcup/at-the-world-cup-doomsday-predictions-give-way-to-smaller-hiccupsin-brazil.html>. Acesso em: 05 jan. 2019.

BRANNAGAN, Paul; GIULLIANOTTI, Richard. Soft power and Soft Disempowerment: Qatar, Global Sport and football's 2022 World Cup finals. Leisure Studies, v.10, p. 1-17, 2014.

BRANNAGAN, Paul; ROOKWOOD, Joel. Sports mega-events, soft power and soft disempowerment: international supporters' perspectives on Qatar's acquisition of the 2022 FIFA World Cup finals. International Journal of Sport Policy and Politics, v. 8, n. 2, p. 173-188, 2016.

CAMPBELL, Kurt; O'HANLON, Michael E. Hard power: The new politics of national security. New York: Basic Books, 2006. 
COOPER, Robert. Hard power, soft power and the goals of diplomacy. In: HELD, David; KOENIG-ARCHIBUGI, Mathias (Ed.). American power in the 21st century. Cambridge: Polity, 2004. p.167-180.

CORNELISSEN, Scarlett. The Geopolitics of Global Aspiration: Sport Mega events and Emerging Powers. The International Journal of the History of Sport, v. 27, n.16-18, p. 30083025, 2010.

CORNELISSEN, Scarlett. More than a Sporting Chance? Appraising the sport for development legacy of the 2010 FIFA World Cup. Third World Quarterly, v. 32, n. 3, p. 503-529, 2011.

DANTAS, Alexis Toríbio; JABBOUR, Elias Marco K.; SOBRAL, Bruno Leonardo B. A recriação conservadora do Estado: impasses no reformismo progressista e popular e o golpe de 2016. Revista da Associação Nacional de Pós-graduação e Pesquisa em Geografia. v.10, n.14, p.5-38, 2016.

DARLINGTON, Shasta. Even before World Cup ball starts rolling, Rio de Janeiro's Olympics under scrutiny. Cable News Network - CNN, Atlanta, 5 junho 2014. Disponível em: <https:// edition.cnn.com/2014/06/05/sport/brazil-rio-olympics-scrutiny/index.html>. Acesso em: 05 jan. 2019.

DAVIES, Wyre. Has Brazil proved World Cup doubters wrong? British Broadcasting Corporation - BBC, Londres, 16 June 2014. Disponível em: <https://www.bbc.com/news/worldlatin-america-27866983>. Acesso em: 05 jan. 2019.

EDITORIALES. Brasil, fracaso deportivo ¿y de país? El Mundo, Madri, 14 julho 2014. Disponível em: <https://www.elmundo.es/opinion/2014/07/14/53c3058fe2704e237b8b458a.html>. Acesso em: 5 jan. 2019.

FREEMAN, Hadley. Favela residents make World Cup work for them with home stays for fans. The Guardian, Londres, World Cup 2014, 23 junho 2014. Disponível em: <https://www. theguardian.com/football/blog/2014/jun/23/favela-residents-world-cup-home-stays-fans $>$. Acesso em: 5 jan. 2019.

GIBSON, Owen. World Cup 2014: five things they said would go wrong in Brazil. The Guardian, Londres, World Cup 2014, 27 junho 2014. Disponível em: <https://www.theguardian.com/ football/2014/jun/27/world-cup-2014-five-things-go-wrong>. Acesso em: 5 jan. 2019.

GRIX, Jonathan; BRANNAGAN, Paul Michael; HOULIHAN, Barrie. Interrogating States Soft power Strategies: a case study of Sports Mega-Events in Brazil and the UK. Global Society, v.29, n.3, p.463-479, 2015.

GRIX, Jonathan, LEE, Donna. Soft power, Sports Mega-Events and Emerging States: The Lure of the Politics of Attraction. Global Society, v.27, n.4, p.521-536, 2013.

HERNANDEZ, Anthony; HOPQUIN, Benoit; BOURCIER, Nicolas. L'improvisation à la brésilienne se révèle à la hauteur de l'événement. Le Monde, Paris, Brésil 2014, 21 junho 2014. Disponível em: <https://www.lemonde.fr/coupe-du-monde/article/2014/06/21//-improvisation-a-la-bresilienne-serevele-a-la-hauteur-de-l-evenement 4442780 1616627.html>. Acesso em: 05 jan. 2019.

HOLSTI, Kalevi Jacque. The Dividing Discipline: Hegemony and Diversity in International Theory. London: Allen \& Unwin, 1985.

HORNE, John; MANZENREITER, Wolfram. An introduction to the sociology of sports mega events. The Sociological Review, v. 54, n. 8, p. 1-24, 2006. 
HORNE, John. Assessing the sociology of sport: On sports mega-events and capitalist modernity. International Review for the Sociology of Sport, v. 50, n. 4-5, p. 466-471, 2015.

HORNE, John. Sports mega-events: three sites of contemporary political contestation. Sport in Society, v. 20, n. 3, p. 328-340, 2017.

HUANG, Yanzhong, DING, Sheng. Dragon's underbelly: An analysis of China's soft power. East Asia, v. 23, n.4, p. 22-44, 2006.

JINKINGS, Ivana; DORIA, Kim; CLETO, Murilo. Por que gritamos golpe? São Paulo: Boitempo, 2016.

LADYMAN, lan. 2014 World Cup is a ball in Brazil as beautiful game wins over sceptics. Daily Mail, Kensington, Sport, 2 july 2014. Disponível em: <https://www.dailymail.co.uk/ sport/worldcup2014/article-2678574/2014-World-Cup-ball-Brazil-beautiful-game-wins-sceptics. html\#ixzz3asmyQJqu>. Acesso em: 05 jan. 2019.

LAFER, Celso. Paradoxos e Possibilidades: Estudos Sobre a Ordem Mundial e Sobre a Política Exterior do Brasil num Sistema Internacional em Transformação. Rio de Janeiro: Nova Fronteira, 1982.

MANZENREITER, Wolfram. The Beijing games in the western imagination of China: The weak power of soft power. Journal of Sport \& Social Issues, v.34, n.1, p.29-48, 2010.

MAYOR, Pere. El fútbol y Brasil. El Mundo, Madri, 19 junho 2014. Disponível em: <https://www. elmundo.es/comunidadvalenciana/2014/06/19/53a1e999ca474197518b4594.htm>. Acesso em: 05 jan. 2019

MBEMBE, Achille. On postcolony. California: University of California, 2001.

MIGNOLO, Walter. La idea de América Latina: la herida colonial y la opción decolonial. Barcelona: Gedisa, 2007.

MORGENTHAU, Hans. A Política entre nações: a luta pelo poder e pela paz. São Paulo: Imprensa Oficial, 2003.

MUGGAH, Robert. How did Rio's police become known as the most violent in the world? The Guardian, London, 3 agosto 2016. Disponível em: <https://www.theguardian.com/globaldevelopment-professionals-network/2016/aug/03/rio-police-violent-killing-olympics-torture>. Acesso em: 5 jan. 2019.

MÜLLER, Martín. What makes an event a mega-event? Definitions and sizes. Leisure Studies, v. 34, n. 6, p. 627-642, 2015.

MUNDIM, Pedro Santos. O viés da cobertura política da imprensa nas eleições presidenciais brasileiras de 2002, 2006 e 20102. Revista Brasileira de Ciência Política, v.1, n.25, p.7-46, 2018.

NYE, Joseph S. Bound to lead: the changing nature of American power. New York: Basic Book, 1990a.

NYE, Joseph S. Soft power: Foreign Policy. Washington Post, n.80, sp. issues $20^{\text {th }}$ anniversary, p.153-171, 1990b.

NYE, Joseph S. Soft power: The means to success in world politics. New York: Public Affairs, 2004. 
NYE, Joseph S. Public Diplomacy and Soft power. The Annals of the American Academy of Political and Social Science, v. 616, p. 94-109, 2008. Disponível em: <https://www.jstor.org/ stable/25097996? seq=1\#page scan tab contents>. Acesso em: 18 dez. 2018.

NYE, Joseph S. Smart power. New Perspectives Quarterly, v. 26, n. 2, p. 7-9, 2009.

PEREIRA, Anthony. Brazil 2014: Exploding the myths of sun, samba, soccer. Cable News Network - CNN, Atlanta, Opinion, 13 junho 2014. Disponível em: <https://edition.cnn. com/2014/06/13/opinion/brazil-sun-sex-soccer/>. Acesso em: 05 jan. 2019.

PLEASANCE, Chris. This is the country lecturing us on climate change? Brazil attempts to teach world a lesson despite its horribly polluted water and deforestation of the Amazon. Daily Mail, London, 6 agosto 2016. Disponível em <https://www.dailymail.co.uk/news/article-3726492/Thiscountry-lecturing-climate-change-Brazil-attempts-teach-world-lesson-despite-horribly-polluted-waterdeforestation-Amazon.html>. Acesso em: 5 jan. 2019.

PREUSS, Holger. The conceptualisation and measurement of mega sport event legacies. Journal of sport \& tourism, v. 12, n. 3/4, p. 207-228, 2007.

PREUSS, Holger; CHRISTIAN Alfs. Signaling through the 2008 Beijing Olympics-Using Mega Sport Events to Change the Perception and Image of the Host. European Sport Management Quarterly, v. 11, n. 1, p. 55-71, 2011.

ROBERTS, Elizabeth. Rio Olympics: Media bus windows shattered, 2 injured. Cable News Network. CNN, Atlanta, 10 agosto 2016. Disponível em: <https://edition.cnn.com/2016/08/10/sport/ rio-media-bus-windows-shatter/index.html>. Acesso em: 5 jan. 2019.

SOUZA, Jessé. A radiografia do golpe. Rio de Janeiro: Leya, 2016.

SZWAKO, José. O fascismo contemporâneo brasileiro ou o mundo segundo o conservadorismo. Revista Escuta, 18 maio 2016. Disponível em: <https://revistaescuta.wordpress.com/2016/05/18/ escuta-especial-conjuntura-o-fascismo-contemporaneo-brasileiro-ou-o-mundo-segundo-oconservadorismo/>. Acesso em: 3 nov. 2018.

THAYALAN, Purshoothe. Des balles perdues et un bus de journalistes attaqué à Rio. Le Figaro, Paris, Le Scan Sport, 10 agosto 2016. Disponível em: <http://sport24.lefigaro.fr/le-scan-sport/ buzz/2016/08/10/27002-20160810ARTFIG00328-des-balles-perdues-et-un-bus-de-journalistesattaque-a-rio.php>. Acesso em: 05 jan. 2016.

TINGLE, Rory. 'We are close in distance, but far away': Rio's slum-dwellers are forced to watch the glittering opening ceremony standing on the roofs of their run-down homes. Daily Mail, Londres, 6 agosto 2016. Disponível em: <https://www.dailymail.co.uk/news/article-3726566/Riospoor-watch-Olympic-opening-rooftops-slum.html>. Acesso em: 05 jan. 2019.

TRAVELMAIL REPORTER. The colourful lives inside football-mad Brazil. Daily Mail, London, 12 junho 2014. Disponível em: <https://www.dailymail.co.uk/video/news/video-1099617/The-colourfullives-inside-football-mad-Brazil.html>. Acesso em: 05 jan. 2019.

WATTS, Jonathan. Rio 2016 could be the moment Brazil sheds its sporting stereotypes. The Guardian, London, Inequality, 10 agosto 2016. Disponível em: <https://www.theguardian.com/ society/2016/aug/10/rio-2016-could-be-the-moment-brazil-sheds-its-sporting-stereotypes>. Acesso em: 5 jan. 2019. 
WATTS, Jonathan; DOUGLAS, Bruce. Rio Olympics: who are the real winners and losers? The Guardian, London, Special report, 19 julho 2016. Disponível em: <https://www.theguardian.com/ cities/2016/jul/19/rio-olympics-who-are-the-real-winners-and-losers>. Acesso em: 5 jan. 2019.

WORLD LATIN AMERICA. Rio 2016: Media bus hit by stone-throwing 'vandals'. British Broadcasting Corporation - BBC, London, World Latin America, 10 agosto 2016. Disponível em: <https://www.bbc.com/news/world-latin-america-37030729>. Acesso em: 05 jan. 2019.

ZIAKAS, Vassilis. For the benefit of all? Developing a critical perspective in mega-event leverage. Leisure Studies, v.4, n.6, p.689-702, 2015. 
